\title{
A Comunicação Cindida ${ }^{1}$
}

\section{Samuel Mateus*}

Resumo: Etimologicamente "comunicação" significa o acto pelo qual algo se torna comum. O problema da comunicação reside no modo como é partilhada e nos objectivos com que é utilizada. A teoria da comunicação surge na modernidade justamente quando o conceito sofre uma ruptura e se divide em dois paradigmas de compreensão: por um lado, um paradigma relacional, substantivo, socio-antropológico; por outro lado, um paradigma transmissivo advindo da tecnologização. Entre um e outro sobrepõe-se a distância que vai da mediação à mediatização. Este artigo procura identificar e caracterizar os dois paradigmas históricos de entendimento da comunicação com vista a separar uma teoria da informação de uma teoria da comunicação.

Palavras-Chave: Teoria da Informação; Teoria da Comunicação;

Resumen: Etimologicamente "comunicación" significa el acto para el cual algo llega a ser común. El problema de la comunicación habita en la manera que es compartida y en los objectivos con que se la utiliza. La teoría de la comunicación aparece justamente en la Modernidad cuando el concepto sufre una ruptura y si divide en dos paradigmas de entendimiento: por una parte, un paradigma relativo, substantivo, socio-antropológico; por otra parte, un paradigma de transmisión y tecnologización. Entre uno y otro se traslapa la distancia que va desde la mediación a la mediatización. Este artículo busca identificar y caracterizar los dos paradigmas históricos de comprensión de la comunicación con proposito de separar una teoría de la información de una teoría de la comunicación.

Palabras Clave: Teoría de la Información; Teoría de la Comunicación;

Abstract: Etymologically "communication" means the act for which something becomes common. The problem of the communication inhabits in the way as it is shared and in the objectives which it is used. The Communication Theory appears exactly in modernity when the concept suffers a rupture and 
it is divided in two paradigms of understanding: in one hand, a relational and substantive paradigm, socio-antropological; on the other hand, a technical and transitive paradigm. Between one and another the distance goes from mediation to mediatisation. This article wants for to identify and characterize the two historical paradigms of understanding of communication in order to separate a information theory from a communication theory.

Keywords: Information Theory; Communication Theory;

Comunicação. O conceito ocupa uma grande parte do vocabulário contemporâneo. Tão abundantemente citado que se acaba por gerar uma névoa que tolda a limpidez que detinha na antiguidade clássica e que impede a diafaneidade do zoon politikon aristotélico. Plasmado em Latim na communicatio ou interpelação retórica, a etimologia de comunicação encontra a sua raiz no verbo communicare cujo significado se bifurca entre o acto de tornar comum ou repartir, e reunir ou associar. Conforme o significado se ancore em uni ou em muni, assim communicare designa a uniformidade do tornar comum ou a comunhão da associação inter pares.

Com efeito, o termo reveste-se de uma duplicidade constitutiva eminentemente contrastante que acentua ora a unicidade ora a diversidade, ora a homogeneidade ora o ecletismo, ora um nível individual ora um nível colectivo. Atendendo ao radical uni, a comunicação denomina o processo de partilha do sentido como transferência de significados, objectos ou pensamentos. A comunicação é perspectivada como translação de sentido entre duas partes, corrimento de significados que se deslocam entre dois pontos separados.

Assim se compreende as estradas como a primeira forma comunicativa global. Comunicar é, nesta acepção unitária, agrupar as diferenças através da partilha do comum. Supõe uma troca pensada como um recrudescimento da transposição, como um fluxo enviado em direcções opostas que salienta um certo grau de mutualidade e de reciprocidade. Neste sentido, as estradas e os mensageiros são historicamente indissociáveis na medida em que tornam possível este lado convergente do processo comunicativo. Do ponto de vista do radical munis, a comunicação é, sobretudo, a emergência de um sentimento comunitário (communitas) e público (communis) capaz de consolidar (communire) a harmonia entre os homens. O munus designava para os Romanos o cargo público que se 
desempenhava mas igualmente a obrigação, a dádiva, o rito funerário ou o espectáculo público. Os combates de gladiadores (gladiatorum munera) simbolizavam esse misto de dever e dádiva públicos que um patrício oferecia aos seus concidadãos como tributo à sociedade. Enfatizando o radical munis, comunicar é renovar o vínculo social que une os indivíduos numa comunhão (e comunicação) horizontal (PETERS, 1999, p.7).

Há, assim, na etimologia de comunicação um sincretismo fundamental entre um sentido prospectivo de partilha de informação e um sentido retrospectivo e memorial de comunhão. Entre o fazer comum e o fazer dádiva, entre a matriz distributiva e a matriz contributiva não existe nenhuma discontinuidade que se torne intransponível. Comunicar é gerir a comunhão, é participar na comunidade fortalecendo-a, ao mesmo tempo que se partilha e se a torna comparticipada.

A comunicação emerge como problema fundamental no momento em que a experiência moderna se desfaz do modo de legitimação transcendente concentrando-se na enunciação, em vez do enunciado, e se pretende instituir sujeito de discurso. Decorrendo da depreciação da experiência tradicional, a modernidade perde o carácter totalizante da experiência. Conforme esta se estilhaça, surgem variados campos sociais cujas diferentes pretensões de legitimidade fazem surgir a comunicação como o processo incumbido de compatibilizar diferentes ordens de valor, e o meio através do qual os campos sociais procedem à intervenção pragmática na sociedade (RODRIGUES, 2008, p.116). Porém, emergência da questão comunicacional na modernidade encontra-se igualmente ligada a uma autonomização da matriz comunal (uni) face à matriz comunitária (munis). $\mathrm{O}$ sincretismo existente entre elas sofre uma ruptura fundamental, cada uma desenvolvendo-se independentemente da outra, em direcções completamente contrárias. Cada matriz comunicacional desenvolve uma lógica de funcionamento própria que negligencia a outra e que contribui para erigir um fosso intransponível. Como resultado deste desmembramento, a comunicação torna-se um processo social espartilhado em práticas diferenciadas e antagónicas entre si. Sofre uma cisão irredutível que a pauperiza porque não tolera mais a conjunção matricial que a fundava na experiência tradicional. A comunicação moderna é uma comunicação esvaziada. Ela contém em si o paradoxo de matrizes comunicacionais incomunicantes.

$\mathrm{Na}$ modernidade, a matriz uniformizadora alcança a preponderância face à matriz comunitária transmutando a comunicação num processo eminentemente reprodutivo em prejuízo do carácter germina- 
tivo. Dá-se, no interior do próprio conceito, como que uma expulsão da matriz comunitária, a qual se vê renegada pela explosão comunicacional que a matriz unificadora do "tornar uno" impõe. De facto, a ascensão da matriz comunal uniformizadora como matriz dominante encontra-se intimamente associada aos dispositivos tecnológicos de mediação simbólica, desde logo com a invenção da prensa de tipos móveis por Gutenberg. Tal é a correlação, que essa ruptura faz da comunicação moderna uma essencialmente tecnologizada. Com efeito, é possível estabelecer a seguinte relação: enquanto a matriz comunitária descreve a comunicação como um processo de mediação simbólica, a matriz comunal atémse quase exclusivamente à sua dimensão mediatizadora.

A partir da autonomização de cada uma das matrizes desenvolveu-se um paradigma de compreensão do fenómeno comunicacional: a matriz comunal deu origem àquilo que denominamos como paradigma transitivo, a matriz comunitária ao paradigma relacional. O paradigma relacional traduz uma visão substancialista do fenómeno comunicacional e comunitário. A comunicação é comunicação, a criação e manutenção da comunidade. Já o paradigma transitivo perspectiva a comunicação como ferramenta e como processo indistinguível de uma mediatização. A comunicação não é substância mas meio, espécie de conduta tecnológica fluida por onde os indivíduos se conectam uns aos outros. Aparelho que se interpõe entre duas partes para tornar possível que elas se aproximem e se fundam numa unidade. A comunicação é, assim, unívoca, única e inequívoca.

\section{O Paradigma Transitivo de Compreensão da Comunicação}

Balizado na enformação Teológica e Física da comunicação (PETERS, 1999, p.63-80), o séc. XIX inaugura uma compreensão da comunicação firmemente ancorada na ideia de transmissão instantânea de mensagens e ideias por intermédio de dispositivos tecnológicos de mediação simbólica. A relação que o homem possui com a comunicação fortemente associada à mediatização é a de uma instrumentalidade. A comunicação é uma espécie de máquina de transporte de pensamentos rompendo com as barreiras espaciais e temporais. A máquina é extrínseca ao homem. Ele usa-a, emprega-a, consome-a como mero aparelho mediatizador e condutor da sua intenção. A comunicação maquinal é 
o seu objecto. $\mathrm{O}$ homem comunica com, através, por meio da técnica, existe separado dela. Ele domina a comunicação dominando a sua mediatização tecnológica.

Compara-se a comunicação a um processo mecânico de transmissão-representação objectiva de conteúdos que um emissor arremessa através de um canal na direcção de um destinatário. Um emissor decide comunicar e um receptor, passivamente, aceita essa acção. $\mathrm{O}$ fenómeno comunicativo é perspectivado como uma conexão entre um agente activo e um agente passivo em que as mensagens transitam por canais directos que ligam as extremidades. É somente uma estocada que se impele através de uma máquina (SFEZ, 1994, p.43).

A comunicação configura, então, uma matéria informe que a mediatização modela. O que significa que é uma extensão, que possui propriedades espaciais e admite a quantificação. Neste caso, a comunicação é susceptível de se tornar ciência e de submeter-se à pesquisa empírica e ao processamento. Ora se a ênfase é colocada na sua mediatização, isto é, na qualidade e fidelidade com que o canal comunicativo transmite, a comunicação torna-se não mais do que uma questão técnica cuja preocupação passa por apurar com que precisão os símbolos podem ser descritos e transferidos, e com que precisão os símbolos transmitidas veiculam a significação pretendida (SHANNON \& WEAVER, 1963, p. 24).

A consequência mais pregnante da autonomização da matriz comunal da comunicação face à matriz comunitária concretiza-se neste olhar técnico da comunicação: informação e comunicação tornam-se termos intermutáveis, praticamente sinónimos apagando qualquer distância que restasse entre teoria da informação e teoria da comunicação. Tomada como informação, a comunicação é alargada não apenas ao contexto de troca de mensagens entre dois sujeitos, como igualmente entre duas máquinas ou entre uma máquina e um indivíduo. É a partir da sobreposição de informação e comunicação que se torna exequível uma teoria cibernética da sociedade ou mesmo uma teoria dos sistemas, a partir das quais, natureza e sociedade são avaliadas como sistemas informacionais (WIENER, 1948). A comunicação-informação é parte integrante dos fenómenos, quer naturais, quer sociais, quer artificiais ou tecnológicos. Tudo se pode explicar em termos de relações informativas entre agentes. Tudo é comunicável porque tudo é informação ou migra- 
ção. O homem vive implicado em correntes contínuas de troca informacional com o exterior.

A comunicação torna-se, então, modelizada tendo por objectivo a previsão e o cálculo logarítmico da sua probabilidade. Ela visa reduzir a imprevisibilidade e a desordem pelo que é considerada, em termos termodinâmicos, como entropia negativa (RUYER, 1954, p.114). Como informação ela é definida ingenuamente não somente de forma binária, como também como um coeficiente entre as possibilidades de ser transmitida e as realizações efectivas da transmissão. A comunicação é, pois reduzida, a pura transmissão técnica. "No sentido mais lato, existe comunicação sempre que um sistema, uma fonte influencia outra, o destinatário, por manipulação de símbolos alternativos que podem ser transmitidos através do canal que as liga" (OSGOOD et al. apud MCQUAIL et WINDAHL, 2003, p.12).

É ao assimilar o tratamento técnico e massivo da informação ao conceito de comunicação que esta adquire novas tonalidades semânticas, as quais reforçam a adesão ao paradigma transitivo de compreensão. Concebida como dispersão, a comunicação é tratada como comunicação de massa pretendendo tratar dos processos gerais de difusão.

Por conseguinte, a comunicação ilusoriamente considerada informação recebe três significações que aludem a mecanismos de processamento de informação em ampla escala: dado (data), notícia (news) e conhecimento (knowledge). A sociedade da comunicação é esse estágio civilizacional do predomínio das tecnologias de processamento da informação em que as redes telemáticas alimentam de dados os dispositivos tecnológicos de mediação simbólica que os transformam em notícias e que, por sua vez, a audiência deve transmutar em conhecimento.

Conforme é evidente, trata-se de uma amálgama num único conceito - ele próprio já combinado com o de comunicação - de significações díspares que estão na origem de perigosas assunções. Uma delas é que o trânsito intenso de informação não apenas é conhecimento, como ainda, é comunicação. Na verdade, muitas actividades profissionais baseiam-se nesta premissa fazendo equivaler a telecomunicação a uma comunicação genuína. Como se quanto mais as sociedades fossem dominadas por dispositivos tecnológicos de mediação simbólica melhor comunicassem e, por consequência, mais prósperas fossem. Os mercados económicos, por exemplo, apropriaram-se da compreensão transitiva da comunicação para a transformar num fluxo que supostamente melhoraria a sua efectividade junto dos consumidores (marketing, public relations, 
advertising, corporate communication). Para eles, o trânsito e a transferência de informações corresponde estritamente a uma prática comunicacional (COOLEY, 1930, p.85). Problemas organizacionais e problemas sociais são apreendidos do mesmo modo. A comunicação é reduzida a uma finalidade operativa.

Encarada na sua transitividade, a comunicação traduz uma visão causal não sendo senão a causa de um efeito. Preocupa-se em determinar um modelo explicativo baseado no pressuposto de determinação da conduta com vista à produção de determinado resultado.

É assim que surge, no início do séc. XX, uma explicação da relação directa entre a comunicação de massa dos dispositivos tecnológicos de mediação simbólica e as suas consequências ao nível do comportamento individual. Imbuída de behaviorismo, a teoria hipodérmica identifica na comunicação um dispositivo capaz de injectar valores e modos de estar nos indivíduos sem que eles possam impedi-lo. Perante o estímulo, os sujeitos desenvolveriam irremediavelmente a mesma resposta. O tema dos efeitos ocupava, assim, a maior parte das teorias da comunicação e durante esse período o conceito de comunicação apontava para a disseminação de mensagens e símbolos persuasivos com vista à manipulação da opinião pública. Lippmann (1922), Bernays (1923) e Lasswell (1927) divisavam na comunicação de massa um mecanismo de produção do consentimento e de propaganda que influenciava e controlava as acções e os pensamentos das pessoas.

De resto, as modelizações de que a comunicação-informação foi objecto, ainda que pretendam proceder à superação da teoria hipodérmica fazendo intervir a influência de outros sujeitos no processo comunicativo, traem, na realidade, esta herança transitiva da comunicação concebendo-a sobretudo com uma relação transmissiva entre emissor e receptor através de código que passa num canal. O célebre modelo de Lasswell (1948) faz ressoar ainda uma comunicação confundida com informação na qual os processos de emissão e de recepção são assimétricos e intencionais. O seu objectivo é obter um efeito capaz de ser percepcionado e avaliado e onde as relações informais são tidas, por defeito, como irrelevantes para o processo de comunicação de massa.

Mesmo os modelos posteriores que acrescentam instâncias de resistência (nomeadamente a dimensão perceptiva e a sociabilidade) que os destinatários opõem à acção dos dispositivos tecnológicos de mediação simbólica, como por exemplo, Newcomb (1953), Schramm (1954), Katz, Lazarslfed (1955), Gerbner (1956), Westley, MacLean (1957), in- 
tegram-se ainda neste paradigma transitivo de compreensão do fenómeno comunicacional. ${ }^{2}$ Romances como 1984 de Orwell (escrito em 1948) ou Brave New World de Huxley (publicado em 1958) surgem impregnados de uma desconfiança que versa um poder penetrante, disciplinar e omnipresente da comunicação.

Em síntese, o paradigma transitivo compreende a comunicação como um processo técnico de difusão em massa de ideias interiores que são acolhidas em formas exteriores que procedem à sua mediatização tratando-as como pacotes matemáticos de informação, os quais são impulsionados através de canais físicos. $\mathrm{O}$ princípio que o funda é o da circularidade de dados, notícias e conhecimentos por intermédio de redes técnicas que permeiam as sociedades tornando-as sociedades transparentes, explícitas e denotativas, numa palavra, sociedades de informação ou de telecomunicação. No paradigma transitivo, a comunicação é teleológica visando sempre algo mais que lhe escapa: é preciso comunicar mais e comunicar melhor, é preciso que a sua linearidade se mantenha intacta, não seja interrompida e se insira em sequências comunicativas que peçam o seu reactivamento permanente. Ela é explosiva atingindo tudo e todos à sua passagem, abrindo caminhos comunicantes e canais de ligação entre partes insuladas. Ela expande-se conquistando o recôndito, acometendo o privado, apossando-se do impronunciável, unificando, empalidecendo a diferença. Esta infocomunicação é invasiva, uma questão de transmitir sem ruído uma mensagem por um canal. Nada a pode deter. Nada porque é uma comunicação por essência transitiva.

\section{O Paradigma Relacional de Compreensão da Comunica- ção}

A comunicação, mais do que da ligação, insere-se numa ordem relacional, distante de uma prática remissiva e reticular. Ela suplementa essa sua dimensão técnica. A comunicação é sempre uma prega, um acidente circunvalado, uma ruga sobre a lisura da ligação. $\mathrm{O}$ fenómeno comunicacional é relação, versa os espaços lacunares, a porosidade primordial, as dissimulações, a ambiguidade. Comunicar não é somente ligar, transmitir, mediatizar. Não é apenas a teleologia da acção instrumental, do trânsito iterativo infindável, do funcionamento contínuo. A comunicação como fenómeno das sociedades humanas constitui-se de 
duplicidades, de exorbitantes, de imponderáveis. A comunicação relacional supõe a interrupção, os cortes de transmissão, as irregularidades imperfeitas, os incidentes acidentais. $\mathrm{O}$ fim da transparência não pressupõe a anulação da comunicação. $\mathrm{O}$ seu insucesso pode significar aproximação. Uma que não encurta mas que estende, uma que não cola mas amplia, que reduplica, que concilia, que impede a coincidência e proíbe o contacto. A comunicação é relação. A relação é o paradoxo do distanciamento que avizinha. Da afinidade que difere. Da comunhão que une sem unificar.

Não obstante a sua justificação comunicacional, a informação não é comunicação. A informação é da ordem tecnocrática, de uma compreensão redutora que não faz implicitamente comunicação, comunhão, comunidade. ${ }^{3}$ Compreende a interpretação, mediatização e acomodação simbólica da realidade de modo a que seja transmitida pelos dispositivos tecnológicos de mediação simbólica. Prende-se com uma dimensão probabilística na qual um acontecimento é tanto mais informativo quanto mais imprevisível e inesperado for. A informação acontece, ocorre, emerge espontaneamente situando-se fora do controlo humano. A sua natureza assimétrica e irreversível traduz-se na sua transmissão unilateral (RODRIGUES, 1999, p.21).

Pelo contrário, a comunicação tem a ver com um mundo cultural dotado de previsibilidade e inferencialidade a partir do qual a intercompreensão se torna possível. Ocorre segundo o princípio da reciprocidade e da reversibilidade num processo de intercâmbio simbólico não apenas gerador de sociabilidade como de laços sociais profundos. A comunicação insemina a relação intersubjectiva com a complexidade do horizonte colectivo, da pluralidade, do dialogismo. Se as redes telemáticas possuem hoje a capacidade de acelerar os processos transitivos de transmissão de informação, encontram-se desprovidos da propriedade relacional que transforme o fluxo global ininterrupto na abundância simbólica que respeite os tempos humanos e os integre numa experiência simultaneamente particular e plural.

Falta à informação a competência que a comunicação encerra e que consiste em aliar experiência individual e experiência colectiva. Enquanto a informação lida principalmente com o processamento discreto de signos ou sinais, a comunicação existe na indiscrição da dimensão simbólica do homem, uma para a qual ele próprio concorre e elabora (RODRIGUES, 1999, p.37). O homem comunica na medida em que fabrica as mediações simbólicas de que necessita no seu mundo cultural, 
ao qual ele assiste ao mesmo tempo que o projecta. A teoria da informação, que no séc.XX (es)bateu a teoria da comunicação, decorre da aplicação mecânica de princípios das ciências naturais, os quais se revelam inaptos para descrever a riqueza mas também a ambiguidade de que os processos comunicativos humanos se revestem. Sob a égide do controlo e do desejo de aumentar a velocidade e a amplitude geográfica das mensagens, ela tende a reduzir a comunicação a uma simples transmissão negligenciando a sua fundamentação cultural e intersubjectiva.

A teoria da informação preocupa-se com a rentabilidade, a eficácia e a economia da transmissão de mensagens entre indivíduos. Pelo contrário, uma teoria da comunicação centra-se no problema de harmonizar sujeitos sem que renunciem à sua irredutibilidade constitutiva. Trata-se, não de os massificar, mas de os humanizar, de gerir a passagem da subjectividade à intersubjectividade, a mutação do individual em colectivo, de orquestrar a criação mundo que contenha o espaço do indivíduo ao mesmo tempo que o espaço social, uma comunidade.

Comunicar é dirigir a orquestra comunitária, marca o compasso, acelerar o seu batimento uníssono (WINKIN, 2001, p.90). A sua tarefa é a criação de um mundo público, comum, comungado. A superioridade da comunicação face à informação advém da preeminência da comunhão do pensamento sob a partilha do pensamento. Se a informação torna comum, faz uno, homogeneíza, a comunicação faz-se plural, diferencial segundo o modo da relação, um que conjuga a associação, a fraternidade e a participação. A tarefa da comunicação concentra-se em tornar possível a feitura da comunidade abrindo as brechas que permitem tornar os universos individuais comunicantes. "A comunicação pode, só por si, criar a grande comunidade. A nossa Babel não é uma de línguas mas de signos e símbolos sem os quais a experiência partilhada é impossível” (DEWEY, 1991, p.142). Fazer a comunidade é fazer brotar o entendimento das subjectividades e fazer brotar um horizonte comungado por todos. É tomar parte num mundo colectivo, anunciando a sua subjectividade, não como uma mercadoria que se transporta entre duas partes, não como uma revelação gratuita de si, mas como uma identificação e responsabilização entre sujeito, alteridade e a sua comunidade de pertença. Comunicar é orquestrar a acção comum, é subordinar a comunidade aos indivíduos interpelando-os a realizá-la.

A comunicação dirige-se, não para a extensão espacial de mensagens, mas para a contracção simbólica que permite a manutenção tem- 
poral da sociedade através de sucessivas gerações. Como salienta Sapir, "é óbvio que na construção da sociedade, as suas unidades e subdivisões, e na compreensão que prevalece entre os seus membros, são necessários alguns processos de comunicação" (1935, p.78). À comunicação, em sentido forte, não lhe interessa a disseminação informacional mas a comunhão das crenças que sustentam o edifício comunitário e que atrai centripetamente os comunicantes.

De certo modo, a comunicação adquire nuances rituais que permitem pensá-la como um cimento que solidifica as sociedades independentemente das suas concretizações históricas. A actividade comunicacional expressa a construção e conservação de uma ordem cultural estruturada e significante que serve como horizonte da acção humana. "A sociedade identifica-se com a influência que os homens exercem sobre outros homens; e como esta influência é uma questão de comunicação, a história desta é a fundação de toda a história" (COOLEY, 1897, p. 74). Essa estruturação simbólica existe para providenciar a confirmação e a reiterabilidade de que a cultura necessita para existir e sustentar o processo social. Em sentido pleno, a comunicação é o processo simbólico sobre o qual a realidade social é produzida, reparada, reproduzida e transformada. Assim concebida, ela descreve o modo com a ordem social (macrosociologia) é realizada ao nível das interacções (microsociologia) (CRAIG, 1999, p.144).

É a partir deste fundo simbólico em perpétua regeneração que pode ocorrer o vínculo social que torna as comunidades e a vida associativa possível. "Aprender a ser humano passa por desenvolver, através do dar e receber da comunicação, um sentido efectivo de ser um membro individualmente distinto da comunidade" (DEWEY, 1991, p.154). O fenómeno comunicacional é uma construção que os comunicantes erguem de cada vez que pretendem reconhecer-se como parceiros que se filiam na interdependência mútua de uma mesma dinâmica social. Mostra-se como um modo de convocação e de coordenação pública da acção. De um ponto de vista normativo, pode ser entendido como interacção, diálogo e deliberação fazendo da linguagem o intermediário da intercompreensão, a qual passa a ser o seu grande objectivo (HABERMAS, 1984).

A comunicação é esse processo que envolve por inteiro as sociedades humanas em que, embora frequentemente não se faça manifestar, subjaz a toda e qualquer relação. Estudá-la é confrontar o modo como 
as formas simbólicas não apenas são criadas, apropriadas, utilizadas e comungadas nas sociedades pelos indivíduos, como também alteram a realidade social observável (CAREY, 1992, p.30).

Esta afirmação implica um corolário primordial. Se a comunicação se insere numa sociologia compreensiva, se ela é o arquitecto simbólico das sociedades, então, à comunicação não lhe pode ser imputável uma essência ou um conjunto de propriedades imutáveis. Isto significa duas coisas. Em primeiro lugar, ao contrário da informação, a comunicação não pode ser simplesmente identificada com um dispositivo técnico. A sua essência é, antes de mais, simbólica. Em segundo lugar, a comunicação pode ser vista como um processo flexível e regenerativo que se pode apresentar historicamente de acordo com práticas simbólicas diversas. Ela não possui uma única modalidade de acção revelando um acentuado sentido evolutivo e adaptativo. ${ }^{4}$

Isto leva-nos a afirmar que o paradigma transitivo e o paradigma relacional de compreensão da comunicação, se quisermos, as matrizes comunal e comunitária, as experiências moderna e tradicional, coexistem nas sociedades contemporâneas. Embora nestas a informação seja a ideologia dominante, a verdade é que podemos encontrar em formas paradigmáticas da informação (como a imprensa escrita ou audiovisual), exemplos de práticas simbólicas de pendor fortemente comunicacional. A leitura de uma notícia poderá, em certos casos, não ser apenas a migração simples e objectiva de um conjunto de ideias mas uma ocorrência em que sejam mobilizadas práticas simbólicas que digam respeito ao sentido comunitário e ao papel social do indivíduo que a comunicação, em sentido pleno, gere (CAREY, 1989, p.20).

Coexistindo os paradigmas, onde residirá o mistério da comunicação?

O enigma da comunicação consiste na determinação da proporção certa entre a matriz comunal e comunitária da comunicação. Uma comunicação que prescinda da comunhão reduz-se a simples transmissão culminando na implausibilidade da informação. Uma comunicação que prescinda da partilha não pode tornar-se efectiva e redundante. $\mathrm{O}$ fenómeno comunicacional caracteriza-se, pois, pelo paradoxo de tornar universal a singularidade, ou seja, ele introduz-nos o Outro ao mesmo tempo que nós nos hospedamos na alteridade. Revela-nos a singularidade do Outro enquanto comunica a comunidade, enquanto nos comunica como seus membros, e como indivíduos de uma mesma pertença. 


\section{Referências}

BERNAYS, Edward. Crystallizing Public Opinion. New York: Boni and Liveright, 1923.

Carey, James W. Communication as Culture - essays on media and society. New York: Routledge, 1992.

COOLEY, Charles Horton. The Process of Social Change. Political Science Quarterly, 12, 1897.pp. 63-81

The Theory of Transportation In: Sociological Theory and Social Research: Being Selected Papers of Charles Horton Cooley, New York, Holt and Company, pp. 17-118. 1930.

CRAIG, Robert T. Communication Theory as a Field. Communication Theory, no2, pp. 119-161. 1999.

DEWEY, John. The Public and its Problems. Ohio University Press, 1991.

GERBNER, George. Toward a General Mode of Communication. Audio-Visual Communication Review, 4, pp.171-199. 1956.

HABERMAS, Jürgen. The Theory of Communicative Action (2 vol), Boston, Beacon Press, 1984.

LASSWELL, Harold. Propaganda Technique in the World War. New York, Knopf, 1927.

. The Structure and Function of Communication in Society In Bryson (ed) The Communication of Ideas. New York: Harper, 1948.

KATZ, Elihu; LAZARSFELD, Paul. Personal Influence, Glencoe, Free Press, 1955.

LIPPMANN, Walter. Public Opinion. New York, Hartcourt Brace and Company, 1922.

MCLUHAN, Marshall. Understanding Media: The Extensions of Man, New York, McGraw Hill, 1964.

MCQUAIL, Dennis; WINDAHL, Sven. Modelos de Comunicação-para o estudo da comunicação de massas. Lisboa: Editorial Notícias, 2003. 
NEWCOMB T. An Approach to the Study of Communicative Acts. Psychological Review, 60, p.393-404, 1953.

PETERS, John Durham. Speaking into the Air- a history of the idea of communication. Chicago: The University of Chicago Press, 1999.

RODRIGUES, Adriano Duarte. Comunicação e Cultura- a experiência cultural na era da informação. Lisboa: Edições Presença, 1999.

Experiência Moderna e Comunicação. Revista Fronteiras - estudos midiáticos X (2), p.111-120. 2008.

RUYER, Raymond. La Cybernétique et l'Origine de l'Information. Paris, Ernest Flammarion, 1954.

SAPIR, Edward. Communication. Encyclopedia of the Social Sciences, 4, pp.78-81. 1935.

SCHRAAM, Walter. How Communication Works In: Schraam (ed) The Process and Effects of Mass Communication. Urbana, University of Illinois Press, 1954.

SFEZ, Lucien. Crítica da Comunicação. Lisboa, Edições Piaget, 1994.

SHANNON, Claude; WEAVER, Warren. The Mathematical Theory of Communication. University of Illinois Press, 1963.

WESTLEY, Bet MacLean M, A Conceptual Model for Mass Communication Research. Journalism Quarterly, 34, pp. 31-8. 1957.

WIENER, Norbert. Cybernetics or Control and Communication in the Animal and the Machine. Cambridge, MA: MIT Press, 1948.

WINKIN, Yves. Anthropologie de la Communication - de la théorie au terrain. Paris: Éditions du Seuil, 2001.

\section{Notas}

[1] Este artigo é uma versão revista e modificada do texto apresentado no $6^{\circ}$ Congresso SOPCOM (Lisboa, Universidade Lusófona), em Abril de 2009.

[2] Ressalve-se que não estamos a assimilar a teoria hipodérmica à teoria dos efeitos mínimos da comunicação, uma vez que são notoriamente contrastantes. Trata-se somente de enfatizar a partilha da mesma compreensão transitiva da comunicação. 
[3] Eis porque o aforismo da "aldeia global" de McLuhan (1964) vive encravado em dois sérios problemas: por um lado, ele é uma interpretação transitiva da comunicação fazendo confundir exponenciação tecnológica e exponenciação do vínculo social. Por outro lado, toma por relação aquilo que pertence à simples ligação telemática (telecomunicação). Ao fazê-lo mistura a experiência moderna da ligação com a experiência tradicional da relação, a comunicação técnica com a comunicação como comunhão. Sem o saber, MacLuhan assimila o paradigma transitivo e relacional da comunicação no mesmo modelo teórico como se possuíssem lógicas de funcionamento comparáveis. Contudo, comunidade e interactividade (redes telemáticas de comunicação) não são simplesmente integráveis na mesma compreensão.

[4] Aliás, aquilo que, noutra reflexão, nomeámos como "consumação" designa um dos modos comunicacionais que as sociedades contemporâneas põem em prática. Autor, A Figuração do Sujeito - sobre publicidade e consumação nas sociedades contemporâneas, dissertação de mestrado apresentada à FCSH- UNL, 2006 (texto policopiado)

\section{* Samuel Mateus}

Doutorando em Ciências da Comunicação (FCSH- Universidade Nova de Lisboa) e bolsista da Fundação para a Ciência e Tecnologia.

\section{E-mail:}

sammateu@gmail.com 